\title{
Visions for the next five years: ECDC as a sustainable and service-oriented organisation
}

Marc Sprenger (director@ecdc.europa.eu)

1. European Centre for Disease Prevention and Control, Stockholm, Sweden

Citation style for this article:

Citation style for this article: Sprenger M. Visions for the next five years: ECDC as a sustainable and service-oriented organisation. Euro Surveill.

2010;15(19):pii=19564. Available online: http://www.eurosurveillance.org/ViewArticle.aspx?Articleld=19564

The European Centre for Disease Prevention and Control (ECDC) is celebrating its fifth anniversary on 20 May 2010. At the beginning of May I started as the new Director of ECDC: it is both a pleasure and a challenge for me to take up my post and to continue the dedicated work of my predecessor, Zsuzsanna Jakab. Long before the Centre was established, I supported the idea of a European Union (EU)-wide institution concerned with the prevention and control of communicable diseases, coordinating the efforts of the Member States and protecting the health of European citizens. As the first Chair of the ECDC Management Board, I was proud to be among those closely involved in the work of establishing ECDC from the outset.

Since 2005 I have seen recognition of the value of ECDC grow and the Centre has gradually become staffed to a level where it can achieve its full potential. Today, it has around 300 expert staff from 29 countries in the EU and European Economic Area, representing a unique intellectual capital. One of my aims is to continually demonstrate the added value of ECDC to our stakeholders, and to European citizens. With the necessary infrastructure now in place at ECDC, it is my goal to build on the excellent work done so far and strive for clear priorities in our work and a high quality of our scientific outputs. Prioritisation is the key to making the best use of the resources available to us, both human and financial, and to guarantee quality.

ECDC has on numerous instances supported the Member States and the European Commission in addressing old and new challenges and facilitating the exchange of experiences and good practices. The guidance document on the implementation of the new human papilloma virus vaccine [1], the EU-wide electronic surveillance system TESSy [2], rapid risk assessments and daily updates of epidemiological data during the 2009 influenza $A\left(\mathrm{H}_{1} \mathrm{~N}_{1}\right)$ pandemic [3] and the support, provided on request of Italian authorities, during the emergence of a Chikungunya fever outbreak in northern Italy in 2007 [4] are but a few examples.

The meetings organised by the Centre provide an opportunity for Member States to come together and exchange experiences on specific challenges on a national level and on the broader implications for the EU. In today's world, countries support each other with regard to communicable diseases and the impact of measures they take at regional or national level. Personal contacts among experts from various disciplines have facilitated the flow of information and fostered the transfer of knowledge in the EU. Because of the expertise of the Centre and of the Member States, ECDC is fulfilling one of the key tasks set out in its founding Regulation - to provide scientific advice.

A crucial element of the scientific advice produced by the Centre is transparency in concerning the contributors and how evidence and facts were weighted to support the scientific assessment and final conclusions. I will personally ensure that ECDC works closely with its political and technical partners to identify priorities specifically concerning our scientific advice that will be reflected in our annual work programmes and our future long-term visions, and that also serve our partners' needs. Service orientation is a core value of ECDC. I acknowledge the diversity of the public health situation across Europe and it is one of my goals to ensure an appropriate response to the different needs from the Member States.

Communicating scientific findings and providing a platform to exchange good practices is one of the core tasks of ECDC. The scientific journal Eurosurveillance serves as such a platform and, building on years of networking experience, has gained a considerable reputation in the past years. The journal has recently been accepted for an impact factor and the first figure will be assigned for 2011. Eurosurveillance is known worldwide for its capacity to disseminate scientific information rapidly so as to enable public health action where needed - a strength that has attracted many readers and contributors not just from Europe but from all continents, especially during the 2009 pandemic [5]. As publisher of the journal, ECDC grants full editorial freedom to Eurosurveillance, and as ECDC's Director I am personally committed to support Eurosurveillance and to guarantee the editorial independence of the journal. 
Looking to the future, I see ECDC continuing to play a central role in providing EU and Member State policymakers with the evidence base needed to respond to some of the key public health challenges Europe faces: how to respond to antimicrobial resistance, how to drive down the incidence of human immunodeficiency virus (HIV) infection and tuberculosis, assessing the impact of environmental change on the spreading of diseases, and further improving surveillance, preparedness and prevention of infectious diseases. The key to achieve this lies in collaboration, and it is with confidence that I look forward to continuing the excellent work with all ECDC's partners and to take the Centre into the future.

\section{References}

1. Guidance for the introduction of HPV vaccines in EU countries. Stockholm: European Centre for Disease Prevention and Control; 2008. Available from: http://ecdc.europa.eu/en/ publications/Publications/0801_GUI_Introduction_of_HPV Vaccines_in_EU.pdf

2. The European Surveillance System (Tessy). Stockholm: European Centre for Disease Prevention and Control; 2010. Available from: http://ecdc.europa.eu/en/activities/ surveillance/Pages/Surveillance_Tessy.aspx

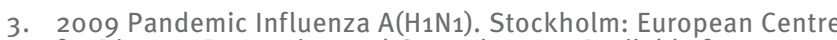
for Disease Prevention and Control; 2010. Available from: http://ecdc.europa.eu/en/healthtopics/H1N1/Pages/home. aspx

4. Depoortere E, Coulombier D, ECDC Chikungunya risk assessment group. Chikungunya risk assessment for Europe: recommendations for action. Euro Surveill. 2006;11(19). $\mathrm{pii}=2956$. Available from: http://www.eurosurveillance.org/ ViewArticle.aspx?Articleld $=2956$

5. Steffens I, Ekdahl K. Eurosurveillance - keeping an eye on infectious diseases. Euro Surveill. 2010;15(1). pii=19452. Available from: http://www.eurosurveillance.org/ViewArticle. aspx?Articleld $=19452$ 